\title{
Prevalence and Intensity of Ancylostoma Duodenale and Necator Americanus Infestations in School Children from the Lolodorf Health District (Cameroon)
}

\section{Djuikwo Teukeng $\mathrm{FF}^{1}$, Kamdem Polla $\mathrm{H}^{2}$, Nkengazon $\mathrm{L}^{3}$, Simo J. ${ }^{4}$, Moyou-Somo $\mathrm{R}^{\star, \dagger, 5}$}

\author{
${ }^{1}$ Faculty of Health Sciences, Université des Montagnes, POBox 208 Bangangté, Cameroon \\ ${ }^{2}$ Faculty of Health Sciences, Université des Montagnes, POBox 208 Bangangté, Cameroon \\ ${ }^{3}$ Institute of Medical Research and Medicinal Plants Studies/Medical Research Centre, Yaoundé \\ ${ }^{4}$ Institute of Medical Research and Medicinal Plants Studies/Medical Research Centre, Yaoundé \\ 5 Institute of Medical Research and Medicinal Plants Studies/Medical Research Centre, Yaoundé
}

DDOI:https://doi.org/10.15520/jcmro.v2i03.140

Accepted 20-03-2019; Received 14-03-2019; Publish Online 28-0-2019

Reviewed By: Dr.

Richard George

Boudreau

Department:

Reviewer/CMRO

\begin{abstract}
Parasitological investigations on Ancylostoma duodenale and Necator americanus infestations were carried out in 541 school children from Lolodorf health district, South Region of Cameroon. Their stools were analyzed using the Kato-Katz technique and the faecal culture of hookworm eggs. Among the 541 children investigated, 4 were infested with $A$. duodenale $(0.7 \%), 13$ with $N$. americanus $(2.4 \%)$ and 11 were co-infested with both nematodes species $(2.3 \%)$, giving a global prevalence of $5.17 \%$. No significant difference between these prevalences in relation to the child sex or age was noted. The low prevalence found for these hookworms could be attributed to mass deworming campaigns against soil transmitted helminths implemented in Cameroon.
\end{abstract}

Key words: Ancylostoma duodenale and Necator americanus Lolodorf health district-Cameroon

\section{INTRODUCTION:}

Human hookworm infestation is caused by blood-feeding nematode parasites of the species Ancylostoma duodenale and Necator americanus. This disease occurs in all countries with a hot and wet climate. According to the World Health Organization, 740 million people are infested by this parasitosis. Among them, 150 million are heavily affected and the disease causes an average 65,000 deaths per year [1] [2] (Albonico, 2004; Brooker et al., 2004). Hook-worms are among the most prevalent causes of mother \& child morbidity in the tropical and subtropical regions of developing countries [3] (Hotez et al., 2006). Schoolchildren (5-15 years) are the most affected, especially in countries with poor environmental hygiene [4] (Luong, 2003). Accord-ing to [5] Olsen et al. (2001), this soiltransmitted helminthi-asis is related to the absence of latrines, whereas [6] Holland et al. (1988) showed a relationship between this infestation and the low socioeconomic level of a country.

* Corresponding author.

$\dagger$ Email: roger_moyou@yahoo.fr
Many studies conducted in sub-Saharan Africa did not attempt to differentiate between the 2 human hookworm species because it was assumed that $N$ americanus was practically the only species present in this zone [7] [2] (Tchuem Tchuenté et al 2013; Nkenngazong et al 2016/ Rujeni et al 2017; Brooker et al. 2009) The presence of $A$ duodenale was however noted in Nigeria [8] [9] (Adenusi, 1997, Adenusi and Ogunyomi 2003) and in Cameroon [7] (george et al 2017). Species identification is usually done using morphological characteristics of third-stage larvae, from eggs in faecal-culture [10] (WHO, 1991). The present study was undertaken to search whether $A$ duodenale was present in south Region of Cameroon, a zone where the prevalence and parasite loads of STHs are very high [11] [12] (Tchuem Tchuente et al 2013, Nkengazong et al. 2018)

\section{METHODS:}

\section{Study site:}

Lolodorf health district is located in the South Region of Cameroon near the western coast of Africa in the Atlantic littoral evergreen forest $\left(10^{\circ} 28^{\prime} \mathrm{E}, 3^{\circ} 07^{\prime} \mathrm{N}\right)$. the climate is 
made-up of four seasons: a long dry season that extend from November to mid-March; a long rainy season that extends from mid-August to November; a short dry season that extends from mid-June to mid-August and a short rainy season that extends from mid-March to mid-June. The annual rainfall ranges from 2,000 to $10,000 \mathrm{~mm}$, being very high where Cameroon's volcanic massif comes close to the coast. In general, the highest rainfall occurs between the months of July and September ranging from 400 to $500 \mathrm{~mm}$ and declines from about $400 \mathrm{~mm}$, in the wet season, to about 100 $\mathrm{mm}$ during the dry season. An annual average temperature of $23-25^{\circ} \mathrm{C}$ has been recorded. Hunting, fishing and farming are the main activities of people in this area [13] (Moyou -Somo et al, 2013 Kengazong et al. 2016). Ten villages belonging to Lolodorf health district including Bihia, Bikoka, Koumbizik, Madong, Matindi I and II, M bande M boulu, Nkouampouer, and Nkonguio, were randomly selected for this survey.

Five hundred and forty one children including 286 boys and 255 girls, aged 4 to 16 years, were recruited according to three criteria: i) children leaving in one of the 10 selected villages, ii) child having permanently stayed in the Lolodorf health district during the six months preceding the onset of the study; iii) child whose parents or guardians have given their informed consent. Children who have received a benzimidazole treatment during the past month and adolescents who have not given their assent were excluded from the study.

\section{Procedure:}

A clean plastic container and instructions on how to collect a fresh stool sample were given to each participant. The samples were collected within 2 hours after the clinical examination of each child. Stools were kept at $-4^{\circ} \mathrm{C}$ until their analysis using the Kato-Katz faecal technique [10] (WHO, 1991) for the identification of hookworm eggs. Positive stools were then cultured at ambient temperature $\left(26^{\circ}\right.$ $28^{\circ} \mathrm{C}$ ) for 48 hours to search for the presence of third-stage larvae. These larvae were examined and identified morphologically using light microscopy.

The first parameter was the prevalence of hookworm infestation in these subjects taking into account their age, their sex, and the parasite species. Differences between the prevalence were analysed using $\mathrm{Chi}^{2}$ test. The second parameter was the egg load, assessed by the number of hookworm eggs per gram of faeces (epg). Individual egg burden were classified into the following three categories: light infestation ( $<500 \mathrm{epg}$ ), moderate infestation (501 to 1000 $\mathrm{epg}$ ), and heavy infestation (>1000 epg). Differences between these categories were also analyzed using $\mathrm{Chi}^{2}$ test.

\section{RESULTS:}

Among the 541 children investigated (Table 1) four were in-fested with $A$. duodenale alone $(0.7 \%), 13$ with $N$. amer-icanus alone $(2.4 \%)$ and 11 with both nematodes $(2.0 \%)$. Boys were slightly more infected than girls but the differ-ence was not significant. Also, no significant difference was noted between the 28 infested children according to their age or sex (Table 2) A. duodenale was noted in $14.3 \%$ of infested children, $N$. americanus in $46.4 \%$ and both nema-todes in $39.3 \%$ (Table 2) The highest number of infected children ( 7 cases) was noted in Nkouampouer village, while the lowest (1case), was recorded in Koumbizik. No infested child was diagnosed in Bikoka.

In the infested children, the following clinical manifestations were noted: abdominal pain (6 children), anaemia (4), pruritus (4), diarrhoea (3), and vomiting (2). The hookworm egg burden was light in 25 children (89.3\%), moderate in 2 children, and severe 1 case.

\section{DISCUSSION:}

In the present study, $N$. americanus was the dominant species, either solely, or in association with $A$. duodenale. This finding agreed with the current knowledge of hookworm infestations in Africa [7] [8] [9] (Adenusi, 1997, Adenusi and Ogunyomi 2003, George et al 2017). The presence of A. duodenale confirms the reports of [8] Adenusi (1997), and [9] Adenusi and Ogunyomi (2003) in Nigeria and suggests that this species would be more widespread in Central Africa than expected. The association of both nematodes in $39.3 \%$ of infected children demonstrated that both nematodes could live in the same individual and confirmed the reports by [14] [8] Oyerinde (1978) and Adenusi (1997).

Overall prevalence of hookworm infestation recorded in the 541 children was low (5.1\%). This finding confirmed the report by [11] Tchuen-Tchuente et al. (2013) who noted a decline in the prevalence of human soil-transmitted helminths in the South province of Cameroon. The result was probably due to mass drug administration (MDA) campaigns implemented by the Cameroonian MOH [11] (Tchuen-Tchuente et al., 2013). In spite of their low values, the prevalences noted for A. duodenale, either solely, or in association with $N$. americanus (a total of $53.6 \%$, (Table 2 ) indicated that $A$. duodenale was rather frequent in the Lolodorf health dis-trict, as this parasite was found in the children of six villages (data not shown).

Hookworm burdens lower than 500 epg (light infestation) were noted in the stools of 25 children, whatever the parasite species ( $89 \%$ of infested children). To explain this finding, the more likely explanation is to relate this finding to the MDA campaigns, as indicated above. However, another explanation, based on concurrence between intestinal helminths for their food and particularly between both nematode species when they are present together in the same host, cannot be completely excluded. Several reports such as that by [4] Lagrue and Poulin (2008) support this last hypothesis.

Limitation of the study: more sensitive and specific techniques such as PCR were not used to distinguish between the 2 human hookworm species and animal species [7] (George et al. 2017) 
Table 1. Distribution of infected children in relation to their sex and parasite species. Prevalences were calculated in relation to the totalnumber of children (first column).

\begin{tabular}{lllll}
\hline \multirow{2}{*}{ Sex (Number) } & \multicolumn{2}{l}{ Number of infected children (prevalence \%) } & & \\
Boys $(286)$ & $2(0.7)$ & $9(3.1)$ & duodenale+N.americanus & Totals \\
Girls $(255)$ & $2(0.8)$ & $4(1.5)$ & $5(2.0)$ & $17(5.9)$ \\
Total (541) & $4(0.7)$ & $13(2.4)$ & $11(2.0)$ & $11(4.3)$ \\
\hline
\end{tabular}

Table 2. Distribution of the 28 infected children in relation totheir age and parasite species. Prevalences were calculated in relation to the total number of infected children (28).

\begin{tabular}{lllll}
\hline \multirow{2}{*}{ Age of children (years) } & \multicolumn{2}{l}{ Number of infected children (\%) } & & \\
& Ancylostoma duodenale & Necator americanus & duodenale+N.americanus & Totals \\
$4-6$ & 0 & 3 & 4 & $7(25.0)$ \\
$7-9$ & 1 & 3 & 4 & $8(28.5)$ \\
$10-12$ & 2 & 4 & 1 & $7(25.0)$ \\
$13-15$ & 1 & 3 & 2 & $6(21.5)$ \\
All children & $4(14.3)$ & $13(46.4)$ & $11(39.3)$ & $28(100)$ \\
\hline
\end{tabular}

\section{CONCLUSION:}

Both nematode species were found in the stools of school children from the Lolodorf health district, with the predominance of $N$. americanus over $A$ duodenale. The low values noted for prevalence and parasitic load of these hookworm infestations were probably due to MDA campaigns implemented by Cameroonian $\mathrm{MOH}$.

Competing interests : The authors declare that they have no competing interest

Authors' contributions: MSR planned the study design; KPH and NL performed field activities; $\mathrm{PKH}$ and SJ performed laboratory investigation; DJFF drafted the manuscript; all authors read and approved the final manuscript.

Acknowledgements: The study was authorized by the "Institutional Review Board of the "Université des Montagnes" (No. 2015/45), the Lolodorf divisional officer, the Chief Medical Officer for the Lolodorf health district and the divisional primary school inspector. In addition, clinical examination of schoolchildren and collection of their stool samples were carried out with the approval of headmasters and teachers. The authors are grateful to Mrs Ngué Monique and Motsebo Amedée, IMPM laboratory technicians, to schoolchildren, and to their parents/guardians, for their cooperation.

\section{REFERENCES}

[1] Albonico M. Methods to sustain dryg efficacy in helminth control programmes. Acta Tropica. 2004;86:233-242.

[2] Brooker S, Peshu N, Warn PA, Mosobo M, Guyatt HL, Marsh K, et al. The epidemiology of hookworm infection and its contribution to anaemia among pre-school children on the Kenyan coast. Transactions of the Royal Society of Tropical Medicine and Hygiene. 1999;93:240-246.

[3] Brooker S, Bethony J, Hotez PJ. Human hookworm infection in the 21st century. vol. 58; 2004.

[4] Lagrue C, Poulin R. Intra- and interspecific competition among the parasites: effects of Coitocaecum parvum life history strategy, size and fecundity. International Journal for
Parasitology. 2008;38:1435-1444.

[5] Olsen A, Samuelsen H, Onyango-Ouma W. A study of risk factors for intestinal helminth infections using epidemiological and anthropological approaches. Journal of Biosocial Science. 2001;33:569-584.

[6] Holland CV, Taren DL, Crompton DWT, Nesheim MC, Sanjur D, Barbeau I, et al. Intestinal helminthiases in relation to the socioeconomic environment of Panamanian children. Social Science and Medicine. 1988;26:209-213.

[7] George S. Kang G, Vercruysse J, Levecke B, editors. Geldhof P, Albonico M, Ame SM, Bethony JM, Engels D, Mekonnen Z, Montresor A, Hem S, Tchuem-Tchuenté LA, Huong NT; 2017.

[8] Adenusi AA. The distribution of Necator americanus and Ancylostoma duodenale among schoolchildren in Lagos. Nigeria Transactions of the Royal Society of Tropical Medicine and Hygiene. 1997;91:270.

[9] Adenusi AA, Ogunyomi EOA. Relative prevalence of the human hookworm species, Necator americanus and Ancylostoma duodenale in an urban community in Ogun Sate. Nigeria African Journal of Biotechnology. 2003;2:370-473.

[10] WHO. Basic laboratory methods in medical parasitology. World Health Organi-zation, Geneva. 1991;61.

[11] Tchuem-Tchuenté LA, Noumedem CD, Ngassam P, Kenfack CM, Gipwe NF, Dankoni E, et al. Mapping of schistosomiasis and soil-transmitted helminthiasis in the regions of Littoral, North-West, South and South-West Cameroon and recommendations for treatment. BMC Infectious Diseases. 2013;13:602.

[12] Nkengazong L, Natchema Soh BOjong L; Amvongo Adjia N. Kame Ngasse G Ngue M; Motsebo A; Moyou-Somo and Ajeagah Aghain-dum. Journal of Current Reseach Accademy Revue. 2018;6(8):83-91.

[13] Moyou-Somo R. Essomba P, Songue E, Tchoubou NN, Ntambo A, Hiol HN, Kemajou JP, Essi MJ. BMC Public Health. 2013;29(13).

[14] Oyerinde JPO. Human Ancylostoma infections in Nigeria. Annals of Tropical Medicine and Parasitology. 1978;72:363367.

[15] Hotez PJ, Bundy DAP, Beegle K, Brooker S, Drake L, Silva $\mathrm{N}$, et al. Helminth infections: soil-transmitted helminth infections and schistosomiasis. Measham, A.R., Alleyne, G., Cleason, M., Evans: Oxford University Press; 2006. p. 467497. 
[16] The molecular speciation of soil-transmitted helminth eggs collected from school children across six endemic countries. Transactions of the Royal Society of Tropical Medicine and Hygiene; 18.

[17] Rujeni N, Morona D, Ruberanziza E, Mazigo HD. Schistosomiasis and soil-transmitted helminthiasis in Rwanda: an update on their epidemiology and control. lnfection Diseases of. Poverty. 2017;6:8.

[18] The molecular speciation of soil-transmitted helminth eggs collected from school children across six endemic countries. Transactions of the Royal Society of Tropical Medicine and Hygiene; 18.

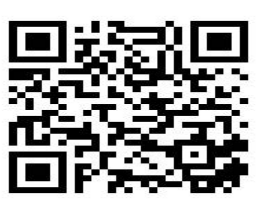

